\title{
Rural outreach by specialist doctors in Australia: a national cross-sectional study of supply and distribution
}

\author{
Belinda G O'Sullivan ${ }^{1 *}$, Catherine M Joyce ${ }^{2}$ and Matthew R McGrail ${ }^{3}$
}

\begin{abstract}
Background: Outreach has been endorsed as an important global strategy to promote universal access to health care but it depends on health workers who are willing to travel. In Australia, rural outreach is commonly provided by specialist doctors who periodically visit the same community over time. However information about the level of participation and the distribution of these services nationally is limited. This paper outlines the proportion of Australian specialist doctors who participate in rural outreach, describes their characteristics and assesses how these characteristics influence remote outreach provision.

Methods: We used data from the Medicine in Australia: Balancing Employment and Life (MABEL) survey, collected between June and November 2008. Weighted logistic regression analyses examined the effect of covariates: sex, age, specialist residential location, rural background, practice arrangements and specialist group on rural outreach. A separate logistic regression analysis studied the effect of covariates on remote outreach compared with other rural outreach.

Results: Of 4,596 specialist doctors, 19\% ( $n=909)$ provided outreach; of which, 16\% ( $n=149)$ provided remote outreach. Most (75\%) outreach providers were metropolitan specialists. In multivariate analysis, outreach was associated with being male (OR 1.38, 1.12 to 1.69), having a rural residence (both inner regional: OR 2.07, 1.68 to 2.54; and outer regional/remote: OR 3.40, 2.38 to 4.87) and working in private consulting rooms (OR 1.24, 1.01 to 1.53). Remote outreach was associated with increasing 5-year age (OR1.17, 1.05 to 1.31) and residing in an outer regional/remote location (OR 10.84, 5.82 to 20.19). Specialists based in inner regional areas were less likely than metropolitan-based specialists to provide remote outreach (OR 0.35, 0.17 to 0.70 ).
\end{abstract}

Conclusion: There is a healthy level of interest in rural outreach work, but remote outreach is less common. Whilst most providers are metropolitan-based, rural doctors are more likely to provide outreach services. Remote distribution is influenced differently: inner regional specialists are less likely to provide remote services compared with metropolitan specialists. To benefit from outreach services and ensure adequate remote distribution, we need to promote coordinated delivery of services arising from metropolitan and rural locations according to rural and remote health need.

Keywords: rural, remote, outreach, visiting, medical, workforce, hub, service planning, policy

\footnotetext{
* Correspondence: Belinda.osullivan@monash.edu

${ }^{1}$ School of Rural Health, Office of Research, Monash University,

Level 3, 26 Mercy St, PO Box 666, Bendigo, Victoria 3550, Australia

Full list of author information is available at the end of the article
} 


\section{Background}

Outreach is defined as the travel by health workers to provide services away from their normal practice. In 2011, outreach was globally endorsed as an evidencebased strategy to improve universal access to health care in underserved areas [1]. Rural outreach by specialist doctors is supported by Australian policy [2,3] and research [4] to overcome workforce shortages, address priority areas of care and provide professional support and education for permanent rural health staff. However, it depends on health workers who are willing to travel and their distribution to areas of need. Historically, specialist doctors in Australia have shown a strong interest and investment in outreach work [3], but we lack systematic information about the proportion of specialists that participate in outreach at a national level, the factors predicting participation in outreach work and the provision of outreach in remote areas.

Medical specialist services are relatively centralized in Australia due to their dependence on a viable population base, other staff and technical equipment [5]. Only $15 \%$ of specialist doctors, in contrast to $31 \%$ of the Australian population, lives in nonmetropolitan (rural and remote) areas [6,7]. Of specialist doctors based in rural and remote areas, most base their practice in large regional towns (approximate population 50,000 to 100,000) [6]. Remote and outer regional locations have the smallest proportion of medical specialists (constituting $13 \%$ and $22 \%$ of all doctors compared with $28 \%$ and $38 \%$ in inner regional and metropolitan areas, respectively) [6].Outside of regional centres, nonmetropolitan Australia is a large country with vast stretches of uninhabited land and a large number of small and dispersed communities, which are located up to $1000 \mathrm{~km}$ from service centres. Remote communities tend to have a higher proportion of indigenous people and widespread poverty. Notably, complex comorbid illness is common, but remote communities have restricted, if any, access to local health care $[8,4]$. Despite greater need, remote outreach is challenging due to extreme distances, rugged terrain, more limited infrastructure and lower clinical throughput [9].

To promote specialist redistribution, the Australian government introduced a national specialist outreach policy in 2000 [3], allocated through a competitive tender process. Specialists can gain subsidization for travel, accommodation, equipment lease, time spent up-skilling and travel time for private specialists (or back-filling for salaried specialists) for providing outreach to rural and remote areas designated to have a service need [3]. Whilst the policy is thought to account for only a small proportion of all outreach services [10] it does signal a sustained national commitment to outreach. Information about the predictors of outreach work and remote distribution will inform policy decisions about how to best target the workforce.

Most Australian specialist doctors can participate in outreach work, either through private arrangements, rights to private practice for hospital specialists [11] or as part of hospital employment conditions [12]; but there is a lack of information about how the main practice arrangements influence outreach work participation. Private practice is quite common among specialist doctors in Australia: only $33 \%$ of specialist doctors work solely in the public sector whereas 19\% solely in the private sector, and $48 \%$ are in mixed sector practice, of which $58 \%$ work mainly privately in hospital or consulting rooms or both [11].

Different types of specialty doctors have the capacity to practice intermittently in small populations [5], but no single analysis has observed how outreach work varies by specialty. Participation by different specialties may be related to rural health need or formal service plans that designate the services needed. Although there is limited information to assess this, core specialty outreach services routinely needed in remote Australian locations have been proposed [13], and rural health strategy in Australia highlights the importance of generalist specialists (for example, general medicine and general surgery) because of their wide scope of practice [14]. Variation by specialty may also be related to labour market conditions. In the Australian context, specialist doctors might be more likely to practice rural outreach work if competition for their specialty services in metropolitan areas is high, for example, when there is an oversupply of a particular specialist type in metropolitan centres. Specialties experiencing workforce shortages, on the other hand, may have less capacity to provide outreach and could experience weaker market influences driving their participation. A number of specialties have been formally assessed at a national level as experiencing current workforce shortages, including psychiatry, medical oncology, general medicine, paediatric surgery and radiation oncology [15].

This paper is the first national study of rural outreach participation by specialist doctors. It aims to outline the proportion of Australian specialist doctors who participate in rural outreach, describe the characteristics of specialists who provide outreach and assess how these characteristics influence remote distribution. Further, it describes the extent of outreach and its remote distribution by specialist type to discuss some of the broad factors influencing participation by specialty.

\section{Methods}

We used data from the Medicine in Australia: Balancing Employment and Life (MABEL) study. It is a large prospective cohort study that conducts annual waves of data collection using a national database of all Australian doctors (https://mabel.org.au/). The first wave was a census of 
the Australian medical workforce able to be contacted and working clinically $(n=54,750)$ between June and November 2008 [16]. Contact details were obtained from the Australian Medical Publishing Company, considered the most comprehensive and accurate listing of all national medical practitioners at the time. Doctors (general practitioners, specialists, specialists in training and hospital non-specialists) were sent an invitation and study information, a paper copy of the survey and were given the opportunity to complete the survey online through a secure website. Three reminders were issued. The survey collected information about job satisfaction, attitudes toward work, work setting, workload, finances, geographic location, demographics and family circumstances [17]. The section on geographic location included questions about the main place of work, main place of residence, and years and location of any childhood rural background. Specialist doctors were also asked whether they travel to provide services/clinics in other geographic areas and were able to list up to three locations (town name and postcode without designating metropolitan or nonmetropolitan locations). A total of 10,498 doctors responded (overall response rate was 19\%). Response bias for the wave 1 sample was reported in a previous study using key covariates of age, sex, geographic location, doctor type and hours worked [16]. It was found to be negligible with the potential to adjust minor bias through weighted analysis.

The primary outcome of this paper, outreach participation, was defined as medical specialist doctors travelling to provide clinics/services in at least one nonmetropolitan location. The secondary outcome, remote outreach participation, was defined as a subset of outreach, where services were provided in at least one remote location. Specialist residential and outreach locations were coded using the 5level Australian Standard Geographical Classification - Remoteness Area scale [18], which is based on the average road distance to nearby larger service centres. The geographic properties of this scale are outlined in Table 1. Nonmetropolitan locations included those categorized as inner regional, outer regional, remote or very remote (an index $>1$ ), and remote locations included those categorized as remote or very remote (an index 4 to 5 ). Specialists who did not report the specific rural town/s they travelled to (for example, reported a broad geographic catchment) were excluded from all analyses because we considered this practice aligned with locum rather than outreach work, which comparatively involves a strong awareness of revisiting specific communities over time.

Specialist residential location was re-categorized to three levels: metropolitan (index $=1$ ), inner regional (index $=2$ ) and outer regional/remote (index 3 to 5).

Specialist doctors were those who had completed advanced training in a technical area of care to gain accreditation with a Specialist Medical College. Main specialty was self-reported from a list of 48 accredited specialties that belonged to one of four main specialist groups (Table 2) [17]. Specialists working in a specialty that was not accredited at the time were able to selfreport 'other specialty - not specified above'.

Age quintiles followed a linear distribution with outreach; thus, age was included as a continuous variable grouped in 5-year increments to aid interpretation.

Rural background was defined as the number of childhood years residing in a rural area up until schoolleaving age ( 0 to 18 years) and was categorized into three groups: 0,1 to 10 and 11 to 18 years.

Private practice was self-reported with three response options: no private practice work (public only), private practice work in a hospital only or private practice in hospital and private consulting rooms.

Cross-sectional sampling weights were applied to all analyses. To determine the predictors of the primary outcome, outreach, bivariate associations of seven covariates (sex, age, location of residence, years of childhood rural background, practice arrangements and specialist group) were tested using logistic regression, odds ratios (OR) and 95\% confidence intervals. In this analysis, four specialist groups were used, comprising individual specialist types as outlined in Table 2. Interactions were tested in adjusted models using the Wald test. A single multiple logistic regression model included all these covariates.

To determine the predictors of the secondary outcome, remote outreach, separate logistic regression analysis was done, which included the same covariates as for the primary outcome. This analysis compared specialists who provided remote outreach with those who provided outreach to other rural areas.

Table 1 Geographic properties of the Australian Standard Geographical Classification - Remoteness Area scale (ASGC-RA) [7,18]

\begin{tabular}{|c|c|c|c|c|}
\hline ASGC-RA index & Label & Australia's population (\%) & Australia's area \% & Density (persons per $\mathrm{km}^{2}$ ) \\
\hline 1 & Major city & $68.6 \%$ & $0.3 \%$ & 780 \\
\hline 2 & Inner regional & $19.7 \%$ & $3.8 \%$ & 16.2 \\
\hline 3 & Outer regional & $9.4 \%$ & $12.5 \%$ & 2.4 \\
\hline 4 & Remote & $1.5 \%$ & $14.6 \%$ & 0.3 \\
\hline 5 & Very remote & $0.8 \%$ & $68.7 \%$ & 0.04 \\
\hline
\end{tabular}




\begin{tabular}{|c|c|}
\hline $\begin{array}{l}\text { Specialist } \\
\text { group }\end{array}$ & Specialist type \\
\hline $\begin{array}{l}\text { Internal } \\
\text { medicine }\end{array}$ & $\begin{array}{l}\text { Cardiology, clinical genetics, clinical haematology, clinical } \\
\text { immunology (including allergy), clinical pharmacology, } \\
\text { endocrinology, gastroenterology, general medicine, } \\
\text { geriatrics, infectious diseases, intensive care-internal } \\
\text { medicine, medical oncology, neurology, nuclear } \\
\text { medicine, paediatric medicine, renal medicine, } \\
\text { rheumatology and thoracic medicine }\end{array}$ \\
\hline Pathology & $\begin{array}{l}\text { General pathology, anatomical pathology, clinical } \\
\text { chemistry, cytopathology, forensic pathology, } \\
\text { haematology, immunology and microbiology }\end{array}$ \\
\hline Surgery & $\begin{array}{l}\text { General surgery, cardiothoracic surgery, orthopaedic } \\
\text { surgery, otolaryngology, paediatric surgery, plastic/ } \\
\text { reconstructive surgery, urology, neurosurgery and } \\
\text { vascular surgery }\end{array}$ \\
\hline Other & $\begin{array}{l}\text { Anaesthesia (non ICU), dermatology, diagnostic } \\
\text { radiology, emergency medicine, intensive care - } \\
\text { anaesthesia, medical administration, obstetrics and } \\
\text { gynaecology, occupational medicine, ophthalmology, } \\
\text { psychiatry, public health medicine, radiation oncology } \\
\text { and rehabilitation medicine }\end{array}$ \\
\hline
\end{tabular}

Source: MABEL Wave 1 questionnaire [17].

The t-test was used to compare mean age between specialists providing outreach or not and to compare those providing remote versus other rural outreach.

Further, separate univariate logistic regression analysis was undertaken to test the association between specialist types and the primary and secondary outcomes. Twelve specialties consisting of all eight pathology specialties (Table 2) and four internal medicine specialties (clinical genetics, clinical haematology, clinical immunology and clinical pharmacology) were grouped together as 'laboratory-based' because of their strong links with work in that setting. They were used as the reference group because laboratories tend to be centralized. Medical administration and public health specialties were combined into one group, as were cardiothoracic surgery and neurosurgery, due to small cell sizes. For analysis of remote outreach, the same laboratory-based specialty group was used as the reference group. Specialty types individually analysed were general medicine, paediatric medicine, general surgery, orthopaedic surgery, otolaryngology, anaesthesia (non-ICU), dermatology, diagnostic radiology, obstetrics and gynaecology, ophthalmology, psychiatry and other specialties not specified. Remaining specialist types were combined and included as one group due to small cell sizes.

The study was approved by the University of Melbourne, Faculty of Business and Economics Human Ethics Advisory Group (Ref. 0709559) and the Monash University Standing Committee on Ethics in Research Involving Humans (Ref. CF07/1102 - 2007000291).

\section{Results}

Responses were received in Wave 1 from 4,596 specialists ( $22 \%$ of all specialist doctors). Of these, $n=35$ were excluded as they did not list the specific rural location/s they visited. In total, $n=909$ (19\%) provided rural outreach, of which $n=149$ (16\%) provided remote outreach. Of rural outreach providers, $\mathrm{n}=715$ (83\%) were male, $\mathrm{n}=623$ (74\%) were metropolitan-based, $n=618$ had no years of childhood rural background (70\%) and $\mathrm{n}=525$ (61\%) worked in private consulting rooms. Of those providing remote outreach, $\mathrm{n}=112(80 \%)$ were male, $\mathrm{n}=82(66 \%)$ were metropolitan-based, $\mathrm{n}=103(75 \%)$ had no years of childhood rural background and $n=72$ (54\%) worked in private consulting rooms.

Table 3 shows the characteristics associated with outreach provision.

In the fully adjusted multivariate model, outreach was associated with being male (OR 1.38, 1.12 to 1.69), residing in a rural area (inner regional: OR 2.07, 1.68 to 2.54; outer regional/remote: OR 3.40, 2.38 to 4.87 ) and working in private consulting rooms (OR 1.24, 1.01 to 1.53). No significant associations were found for age, specialist group or rural background. No effect modification was evident.

Table 4 shows participation in outreach by specialist type. Compared with laboratory-related specialties, general medicine (OR 1.82, 1.06 to 311), renal medicine (OR 3.26, 1.74 to 6.12), otolaryngology (OR 2.21, 1.13 to 4.34), urology (OR 3.63, 1.72 to 7.67 ), ophthalmology (OR 1.92, 1.17 to 3.14 ) and radiation oncology (OR 2.68, 1.34 to 5.33 ) specialties were more likely to provide outreach. Anaesthetists were less likely than laboratorybased specialties to provide outreach (OR 0.56, 0.37 to 0.84$)$.

Table 5 shows the characteristics influencing remote outreach, compared with other rural outreach. Increasing age (OR 1.17, 1.05 to 1.31) and residing in an outer regional/remote area (OR 10.84, 5.82 to 20.19) were significantly associated with providing outreach in remote locations. Specialists in inner regional areas were less likely to provide remote outreach (OR $0.35,0.17$ to $0.70)$. Specialists working in private consulting rooms tended to be less likely to provide remote outreach, but this was not significant. Sex, rural background and specialist group were not associated with remote provision. No effect modification was evident.

Specialists in general medicine (OR 4.45, 1.30 to $15.15, P=0.017$ ), general surgery (OR $3.89,1.25$ to $12.07, P=0.02$ ), otolaryngology (OR $6.25,1.57$ to 8.26 , $P=0.009$ ) and dermatology (OR 6.62, 1.53 to 28.68, $P=0.012$ ) were more likely to provide remote outreach than laboratory-based specialities. Remote outreach by ophthalmology approached significance (OR 2.99, 0.89 to $10.05, P=0.08)$. 
Table 3 Strength of association between characteristics of Australian specialist doctors and providing rural outreach services

\begin{tabular}{|c|c|c|c|c|c|c|}
\hline \multirow[t]{2}{*}{ Covariates of interest } & \multicolumn{2}{|c|}{ Providing outreach } & \multirow{2}{*}{$\begin{array}{l}\text { Univariate odds ratio } \\
\text { ( } 95 \% \text { confidence interval) }^{a}\end{array}$} & \multirow[t]{2}{*}{$P$ value } & \multirow{2}{*}{$\begin{array}{l}\text { Multivariate odds ratio } \\
(95 \% \text { confidence interval) })^{\text {ac }}\end{array}$} & \multirow[t]{2}{*}{$P$ value } \\
\hline & Yes (n) & $\%$ yes $^{a}$ & & & & \\
\hline Total & 909 & 19 & & & & \\
\hline \multicolumn{7}{|l|}{ Sex } \\
\hline Female & 194 & 15 & Reference & & Reference & \\
\hline Male & 715 & 20 & $1.47(1.22$ to 1.76$)$ & $<0.0001$ & $1.38(1.12$ to 1.69$)$ & 0.002 \\
\hline Age (grouped by 5 years) & 909 & $\begin{array}{l}\text { Mean } 50.9 \text { SD } \\
9.68\end{array}$ & 1.00 (0.97 to 1.04$)$ & 0.06 & 0.98 (0.94 to 1.01$)$ & 0.28 \\
\hline \multicolumn{7}{|l|}{ Location of residence $^{\mathbf{b}}$} \\
\hline Metro & 616 & 17 & Reference & & Reference & \\
\hline Inner regional & 208 & 33 & 2.28 (1.88 to 2.77$)$ & $<0.0001$ & 2.07 (1.68 to 2.54$)$ & $<0.0001$ \\
\hline Outer regional/remote & 78 & 43 & 3.55 (2.54 to 4.96$)$ & $<0.0001$ & 3.40 (2.38 to 4.87$)$ & $<0.0001$ \\
\hline \multicolumn{7}{|l|}{ Years of Rural background ${ }^{b}$} \\
\hline Nil & 618 & 19 & Reference & & Reference & \\
\hline 1 to 10 & 103 & 22 & 1.23 (0.96 to 1.58$)$ & 0.10 & $1.21(0.93$ to 1.56$)$ & 0.16 \\
\hline $11+$ & 174 & 25 & 1.39 (1.14 to 1.70$)$ & 0.001 & 1.24 (1.00 to 1.55$)$ & 0.06 \\
\hline \multicolumn{7}{|l|}{ Practice arrangements ${ }^{\mathbf{b}}$} \\
\hline Public only & 198 & 18 & Reference & & Reference & \\
\hline $\begin{array}{l}\text { Private to hospital and consulting } \\
\text { rooms }\end{array}$ & 525 & 22 & 1.29 (1.06 to 1.56$)$ & 0.01 & 1.24 (1.01 to 1.53$)$ & 0.04 \\
\hline Private to hospital only & 135 & 15 & 0.78 (0.60 to 1.00$)$ & 0.05 & 0.78 (0.60 to 1.02 ) & 0.07 \\
\hline \multicolumn{7}{|l|}{ Specialist group ${ }^{\mathbf{b}}$} \\
\hline Pathologist & 33 & 16 & Reference & & Reference & \\
\hline Surgeon & 146 & 24 & 1.58 (1.03 to 2.44$)$ & 0.04 & 1.34 (0.82 to 2.19 ) & 0.24 \\
\hline Internal physician & 301 & 24 & 1.57 (1.04 to 2.37$)$ & 0.03 & 1.57 (0.99 to 2.49$)$ & 0.06 \\
\hline Other specialist & 425 & 18 & 1.13 (0.75 to 1.68$)$ & 0.50 & 1.14 (0.73 to 1.80$)$ & 0.56 \\
\hline
\end{tabular}

analysis includes cross-sectional sampling weight.

blocation of residence missing for $n=7$ specialists providing outreach and $n=307$ not providing outreach.

years rural background missing $n=14$ specialists providing outreach and $n=359$ not providing outreach.

practice arrangements missing $n=51$ specialists providing outreach and $n=311$ not providing outreach.

specialist group missing $n=4$ specialists providing outreach and $n=357$ not providing outreach. Specialist group included specialist types as outlined in Table 1 .

'Total missing from multivariate model $n=725$.

\section{Discussion}

This study provides the first national perspective of the extent and characteristics of rural outreach by the specialist doctors. Providing rural outreach services is relatively common, suggesting there are both unmet needs/ demands for services and a healthy level of workforce interest. A smaller proportion of specialist doctors provide outreach in remote areas and this is influenced differently. Factors influencing outreach participation, and then remote distribution, are discussed.

Outreach participation was more common among male specialists; $83 \%$ of providers were male. Whilst most Australian specialists (77\%) are male, an increasing proportion of qualified specialists and particularly specialistsin-training are female [19]. Female specialists-in-training increased 4.6\% between 2008 and 2012 [6]. The gender- related influences on the uptake of outreach work will be important to explore, as will the potential to influence uptake by exposure to outreach work during medical training.

Around three-quarters of outreach providers are metropolitan-based, largely because $85 \%$ of Australian specialists reside in metropolitan areas. However, residing in a rural area was strongly related to providing rural outreach. In rural locations, providing services in nearby towns may be relatively convenient, undertaken as part of employment or organizational expectations [12] (under hub-and-spoke regional health models) or provided to increase the viability of regional specialist practice [20]. Furthermore specialists residing in rural locations may be more aware of regional health needs in neighbouring towns [21]. 


\begin{tabular}{|c|c|c|c|c|}
\hline \multirow[t]{2}{*}{ Specialist type } & \multicolumn{2}{|c|}{ Providing outreach } & \multirow[t]{2}{*}{ Univariate odds ratio $\left(95 \%\right.$ confidence interval) ${ }^{b}$} & \multirow[t]{2}{*}{$P$ value } \\
\hline & Yes $(n)^{a}$ & $\%$ yes $^{b}$ & & \\
\hline Lab-based specialties & 51 & 18 & Reference & \\
\hline Anaesthesia (non-ICU) & 68 & 11 & 0.56 (0.37 to 0.84$)$ & 0.006 \\
\hline Cardiology & 20 & 26 & 1.63 (0.87 to 3.03 ) & 0.13 \\
\hline Cardiothoracic surgery/neurosurgery & 5 & 12 & $0.60(0.22$ to 1.63$)$ & 0.32 \\
\hline Dermatology & 14 & 24 & 1.43 (0.70 to 2.92$)$ & 0.33 \\
\hline Diagnostic radiology & 56 & 25 & 1.55 (0.99 to 2.42$)$ & 0.06 \\
\hline Emergency medicine & 24 & 13 & 0.67 (0.38 to 1.15$)$ & 0.15 \\
\hline Endocrinology & 11 & 14 & 0.74 (0.36 to 1.54$)$ & 0.42 \\
\hline Gastroenterology & 14 & 17 & 0.92 (0.47 to 1.80$)$ & 0.81 \\
\hline General medicine & 32 & 28 & $1.82(1.06$ to 3.11$)$ & 0.03 \\
\hline General surgery & 51 & 23 & 1.33 (0.84 to 2.10$)$ & 0.22 \\
\hline Geriatrics & 24 & 28 & $1.82(1.00$ to 3.27$)$ & 0.05 \\
\hline Infectious diseases & 7 & 20 & 1.13 (0.44 to 2.89$)$ & 0.8 \\
\hline Intensive care & 9 & 13 & 0.69 (0.31 to 1.53$)$ & 0.37 \\
\hline Intensive care - anaesthesia & 4 & 13 & 0.69 (0.23 to 2.09$)$ & 0.51 \\
\hline Medical oncology & 16 & 30 & 1.97 (1.00 to 3.86$)$ & 0.05 \\
\hline Neurology & 15 & 28 & 1.75 (0.87 to 3.53$)$ & 0.12 \\
\hline Nuclear medicine & 5 & 15 & 0.82 (0.30 to 2.27$)$ & 0.71 \\
\hline Obstetrics and gynaecology & 51 & 19 & 1.06 (0.68 to 1.67$)$ & 0.79 \\
\hline Occupational medicine & 14 & 27 & 1.72 (0.84 to 3.51$)$ & 0.14 \\
\hline Ophthalmology & 41 & 29 & $1.92(1.17$ to 3.14$)$ & 0.01 \\
\hline Orthopaedic surgery & 36 & 23 & $1.33(0.81$ to 2.19$)$ & 0.26 \\
\hline Other specialty & 46 & 23 & 1.40 (0.87 to 2.23$)$ & 0.16 \\
\hline Otolaryngology & 17 & 33 & $2.21(1.13$ to 4.34$)$ & 0.02 \\
\hline Paediatric medicine & 68 & 25 & $1.56(1.00$ to 2.39$)$ & 0.05 \\
\hline Paediatric surgery & 5 & 24 & 1.44 (0.48 to 4.32$)$ & 0.51 \\
\hline Plastic/reconstructive surgery & 5 & 13 & 0.66 (0.24 to 1.80$)$ & 0.42 \\
\hline Psychiatry & 82 & 19 & 1.04 (0.70 to 1.57$)$ & 0.84 \\
\hline Public health medicine/medical administration & 6 & 22 & $1.32(0.47$ to 3.69$)$ & 0.6 \\
\hline Radiation oncology & 17 & 37 & 2.68 (1.34 to 5.33$)$ & 0.005 \\
\hline Rehabilitation medicine & 13 & 23 & 1.41 (0.69 to 2.86$)$ & 0.35 \\
\hline Renal medicine & 26 & 42 & 3.26 (1.74 to 6.12$)$ & $<0.0001$ \\
\hline Rheumatology & 11 & 23 & 1.34 (0.63 to 2.85 ) & 0.45 \\
\hline Thoracic medicine & 12 & 16 & 0.88 (0.43 to 1.80 ) & 0.73 \\
\hline Urology & 15 & 44 & 3.63 (1.72 to 7.67$)$ & 0.001 \\
\hline Vascular surgery & 11 & 31 & 2.01 (0.89 to 4.54$)$ & 0.09 \\
\hline
\end{tabular}

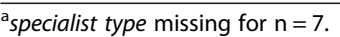

banalysis includes cross-sectional sampling weight.

Specialists working in private consulting rooms are more likely to provide outreach, possibly due to higher practice autonomy. With more control over work choice, individual motivations can play out [12] such as a desire to respond to identified health needs, to expand and diversify the main practice base [12], or provide complex health care in challenging situations [22]. Of the $19 \%$ of specialist doctors who work in private only practices, $71 \%$ have private consulting rooms and of the $48 \%$ who work in mixed public/private practice, $36 \%$ work mainly in private consulting rooms [11]. 
Table 5 Strength of association between characteristics of Australian specialist doctors and providing remote outreach services, compared with any rural outreach

\begin{tabular}{|c|c|c|c|c|c|c|}
\hline \multirow[t]{2}{*}{ Covariates of interest } & \multicolumn{2}{|c|}{ Providing remote outreach } & \multirow{2}{*}{$\begin{array}{l}\text { Univariate odds ratio } \\
\text { ( } 95 \% \text { confidence interval) }\end{array}$} & \multirow[t]{2}{*}{$P$ value } & \multirow{2}{*}{$\begin{array}{l}\text { Multivariate odds ratio } \\
(95 \% \text { confidence interval) }\end{array}$} & \multirow[t]{2}{*}{$P$ value } \\
\hline & Yes (n) & $\%$ yes $^{a}$ & & & & \\
\hline Total & 149 & 16 & & & & \\
\hline \multicolumn{7}{|l|}{ Sex } \\
\hline Female & 37 & 18 & Reference & & Reference & \\
\hline Male & 112 & 15 & $0.79(0.52,1.19)$ & 0.26 & 0.75 (0.45 to 1.25$)$ & 0.27 \\
\hline Age (grouped by 5 years) & 149 & $\begin{array}{l}\text { Mean } 51.8 \text { SD } \\
10.13\end{array}$ & $1.06(0.97$ to 1.16$)$ & 0.18 & $1.17(1.05$ to 1.31$)$ & 0.006 \\
\hline \multicolumn{7}{|l|}{ Location of residence $^{\mathbf{b}}$} \\
\hline Metro & 82 & 14 & Reference & & Reference & \\
\hline Inner regional & 11 & 5 & 0.36 (0.19 to 0.70$)$ & 0.002 & 0.35 (0.17 to 0.70$)$ & 0.003 \\
\hline Outer regional/remote & 54 & 62 & 14.65 (8.59 to 25.00$)$ & $<0.0001$ & $10.84(5.82$ to 20.19$)$ & $<0.0001$ \\
\hline \multicolumn{7}{|l|}{ Years of Rural background ${ }^{b}$} \\
\hline $\mathrm{Nil}$ & 103 & 17 & Reference & & Reference & \\
\hline 1 to 10 & 16 & 13 & $0.92(0.52$ to 1.63$)$ & 0.77 & 0.83 (0.42 to 1.65$)$ & 0.59 \\
\hline $11+$ & 25 & 12 & 0.84 (0.52 to 1.35$)$ & 0.47 & 0.68 (0.37 to 1.25$)$ & 0.22 \\
\hline \multicolumn{7}{|l|}{ Practice arrangements $^{\mathbf{b}}$} \\
\hline Public only & 48 & 21 & Reference & & Reference & \\
\hline $\begin{array}{l}\text { Private - hospital and consulting } \\
\text { rooms }\end{array}$ & 72 & 14 & 0.50 (0.33 to 0.75$)$ & 0.001 & 0.64 (0.39 to 1.06 ) & 0.08 \\
\hline Private - hospital only & 24 & 15 & 0.68 (0.39 to 1.17 ) & 0.16 & 0.65 (0.33 to 1.28$)$ & 0.21 \\
\hline \multicolumn{7}{|l|}{ Specialist group } \\
\hline Pathologist & 5 & 15 & Reference & & Reference & \\
\hline Surgeon & 45 & 20 & 1.38 (0.49 to 3.90$)$ & 0.54 & 1.86 (0.58 to 5.95$)$ & 0.30 \\
\hline Internal physician & 29 & 13 & 0.98 (0.36 to 2.68$)$ & 0.98 & 1.05 (0.34 to 3.18 ) & 0.94 \\
\hline Other specialist & 70 & 16 & 1.10 (0.41 to 2.96$)$ & 0.84 & 1.46 (0.49 to 4.37$)$ & 0.50 \\
\hline
\end{tabular}

analysis includes cross-sectional sampling weight.

blocation of residence missing $n=2$ for specialists providing remote outreach and $n=5$ for those providing other rural outreach.

years rural background missing $n=5$ for specialists providing remote outreach and $n=9$ for those providing other rural outreach.

practice arrangements missing $n=5$ for specialists providing remote outreach and $n=46$ for those providing other rural outreach.

specialist group missing $n=0$ for specialists providing remote outreach and $n=4$ for those providing other rural outreach. Specialist group included specialist

types as outlined in Table 1.

${ }^{\mathrm{C}}$ Total missing from multivariate model $\mathrm{n}=69$.

Despite evidence that rural upbringing can influence the attraction and retention of rural specialist medical staff [23], having a rural background is not significantly associated with outreach. Specialists with a metropolitan upbringing, may value the professional diversity and challenge of intermittent rural practice [22]. It is likely that the dynamics influencing outreach work vary from those influencing permanent rural appointment.

Our study has additionally highlighted key factors influencing the provision of outreach in remote areas. Whilst only $16 \%$ of outreach services were provided in remote areas, only $7 \%$ of Australia's nonmetropolitan population resides in remote locations [7]. Nevertheless, remote service provision is still likely to be under-represented because remote communities are spread across $83.3 \%$ of Australia's land mass, remote health needs are greater than those in rural areas and local specialist services are more commonly not available. Further, the frequency of outreach visiting in remote areas is potentially much lower than in rural areas [4].

Remote outreach is associated with increasing age, suggesting that as professional stability and financial security increases, specialists may be more likely to participate.

Inner regional specialists are the least likely to provide remote outreach, possibly related to the high demand for health care coupled with staff shortages in regional settings [21]. Key logistical barriers may be the time requirements for remote travel [12] and limited efficient travel options to transport them to remote areas (that is, reliance on car travel or the need to travel via major cities to access remote-area flights). Further, they may be more likely to identify, within the region, communities 
that are in need, precluding the need to travel longdistances to fulfil motivations to support underserved populations [12].

Remote outreach tends to be provided by specialists residing either close to or in remote areas or by metropolitan specialists (two-thirds of all remote providers). This suggests that flexible models of service delivery (rather than integrated hub-and-spoke models) currently underpin remote outreach provision [12]. Flexible models may help capitalize on the specialists willing to travel and enable remote areas to tap into metropolitan supply networks. However, where services arise from varied origins, strong local planning processes are paramount to ensure they complement each other, are well integrated with local community-based services and align with local needs and priorities.

Whilst not statistically significant, specialists with private consulting rooms tend to be less likely to provide remote outreach compared with public-only specialists. Private specialists, remunerated through fee-for-service arrangements, may be deterred by lower clinical throughput [9] and loss of income incurred for the longer travel [12] associated with remote outreach practice. Current Australian outreach policy aims to overcome disincentives for private specialists to travel and up-skill local staff, but not all specialist types are eligible for policy support and the funding is limited [3]. Further, the policy does not permit private specialists to nominate to receive a sessional or salaried payment for clinical services rendered during outreach, except in exceptional circumstances [2].

It is common for different specialist types to provide outreach services, some well above the average participation rate of $19 \%$. However the extent of outreach and its distribution to remote areas varies by specialty. There were some discernable patterns in participation according to needs or service plans in the Australian setting. Consistent with rural health strategy [14], generalist specialists are more likely to provide both rural and remote outreach. Additionally, three of seven core outreach services considered needed in remote areas [13] are associated with remote outreach (general medicine, general surgery and otolaryngology), two with rural rather than remote provision, (paediatrics and ophthalmology) and two had no association with rural or remote outreach (cardiology and obstetrics and gynaecology). This suggests health service planning is potentially important to mobilizing specific specialty types. Ideally, this planning is based on systematic assessment of rural and remote health need and existing workforce capacity, at a regional level.

Workforce shortages in some specialties are unrelated to participation in outreach work. For example, general medicine, radiation oncology and psychiatry are considered to be in current workforce shortage [15], but only psychiatrists are less likely to provide outreach services. Addressing the greater relative health need in rural and remote areas could potentially be a stronger driver than market forces. Motivations that affect different types of specialists require further exploration, but evidence to date shows outreach work is not necessarily a profitable undertaking [3].

In addition to, or instead of, outreach services, rural and remote populations may access specialist medical care through a range of other service models and arrangements. These include: 1) role-substitution with general practitioner proceduralists (for example, anaesthetics); 2) telemedicine (for example, psychiatry); 3) aero-medical retrieval (for example, emergency medicine); 4) patient assisted transport or 5) travel (at patient's own expense) to regional or metropolitan centres. Decisions about how to deliver services might be influenced by the preferences of local rural staff and patients, the complexity of care with respect to local infrastructure and rural workforce capacity, how practical and affordable it is for patients to travel and the cost and availability of patient and specialist transport and accommodation. Compared with the alternatives, outreach has the potential to provide up-skilling on site, support complex case management [24], enable simple procedures [20], improve continuity of care [4] and reach populations who are unlikely to otherwise seek care [4], but it may not be timely enough in urgent situations, nor have the capacity to reach all communities in need. The way outreach services are billed is yet to be determined systematically, but economies of scale are expressed where the specialist travels to a group of patients, rather than individual patients to the specialist [20].

This paper reflects patterns of outreach in a nation where specialist doctors have a strong history of selfinitiating rural outreach work, supported by a universal health insurance system and since 2000, a national outreach policy which helps subsidize travel and accommodation for selected specialists [3]. Also, among Australian doctors, specialists are the highest income earners [25], possible enabling them to provide outreach services in situations of no or limited financial benefit [3]. Depending on the state of the population's health and locally available workforce and infrastructure in underserved areas, other nations may decide to mobilize primary, preventative or specialty workforces. Factors influencing the participation by other health workers are likely to vary. But for the workforce of interest, it is important to consider the history of outreach practice, public/private work sector balance, workforce size and current distribution, remuneration arrangements, geographical distances and the availability of expedient travel options. In many countries, distances to rural and remote areas may be smaller than in Australia but 
limited infrastructure, and safety issues may affect mobilisation of the workforce and their travel to remote locations.

Some limitations are acknowledged. This paper was not able to explore the full extent of rural outreach work because the MABEL survey did not collect information about how frequently outreach services were provided to different communities, nor the exact functions the specialist doctors performed at the rural locations they visited. This has potential implications for the type of rural health service capacity achieved by workforce mobilization patterns studied in this paper. The rate of visiting to remote areas is expected to be considerably lower than that to regional areas, but this has not been systematically studied. The MABEL survey is currently collecting information about the frequency of visiting, remuneration arrangements and workforce motivations to address information gaps.

As another limitation, this paper has only examined outreach by specialist doctors, assuming they are visiting in isolation. However, it is possible that participation in outreach is influenced by the ability to visit as part of a complementary health-care team, which helps overcome barriers such as local staff shortages. Whilst we have not analysed outreach with respect to local-level service capacity, we recognize that sustainable outreach is conditional on stable primary health care [26]. Policies to support recruitment and retention of primary health staff (medical, nursing, allied health, indigenous health workers and community volunteers) are likely to improve the distribution of specialist outreach workers, particularly to remote areas. Apart from excluding 35 specialists who did not report the specific locations they visited, this study was not able to further delineate locum from outreach workers due to a lack of information about regularity and length of rural visiting. We tested the effect of excluding specialists who work as hospital locums for more than 15 hours per week in their normal practice $(\mathrm{n}=34$ providing any rural outreach), which did not affect the results. We used cross-sectional data, such that associations, rather than causal relationships could be examined. A cross-sectional snapshot can be informative because evidence shows outreach tends to be sustained for at least five years [12].

We acknowledge that our findings are based on 2008 data, and we are aware that the policy environment has changed somewhat since that time [3]. We expect that many of the predictive factors studied (age, location, specialist type and practice arrangements) have remained relatively stable over time. Our paper provides the first national study of participation in outreach, providing a baseline from which to examine trends over time. We are pursuing further research on longitudinal trends in the context of changes in policy since 2008.
Whilst we used survey weights to control for selection bias, unobserved response bias that cannot be corrected by the use of weights may exist.

\section{Conclusions}

Outreach is relatively common among Australian specialist doctors suggesting there is a need or demand for services and a healthy level of workforce interest. Whilst rural specialists are more likely to provide outreach, metropolitan areas form an important hub, being the main locations where specialists reside. Despite greater need, remote outreach is less prevalent and depends on harnessing specialists based proximally as well as those from metropolitan areas. Whilst having private consulting rooms may influence outreach work, private specialists may be less inclined to provide remote outreach. Coordinated planning to promote outreach by specific specialties, and integrate services arising from different locations, is important to harnessing the benefit of outreach, specific to community need.

\section{Abbreviations}

MABEL: Medicine in Australia: Balancing Employment and Life; OR: odds ratio.

\section{Competing interests}

We declare there are no conflicts of interest in producing this work. The lead author is supported by an Australian Postgraduate Award. This research otherwise received no specific grant from any funding agency in the public, commercial or not-for-profit sectors.

\section{Author's contributions}

$C J$ and MM were involved in collecting the information as part of the MABEL longitudinal survey of doctors. BOS conceived the study, analyzed data, interpreted findings and drafted the manuscript. MM and CJ critically reviewed the study design, analyses and manuscript. All authors read and approved the final manuscript.

\section{Acknowledgements}

This publication used data from the MABEL longitudinal survey of Australian doctors conducted by the University of Melbourne and Monash University (the MABEL research team). Funding for MABEL comes from the National Health and Medical Research Council (Health Services Research Grant: 2008-2011; and Centre for Research Excellence in Medical Workforce Dynamics: 2012-2016) with additional support from the Department of health (in 2008) and Health Workforce Australia (in 2013).

Author details

${ }^{1}$ School of Rural Health, Office of Research, Monash University, Level 3, 26 Mercy St, PO Box 666, Bendigo, Victoria 3550, Australia. ${ }^{2}$ Department of Epidemiology and Preventive Medicine, The Alfred Centre, Monash University, Level 6, 99 Commercial Road, Melbourne, Victoria 3004, Australia. ${ }^{3}$ School of Rural Health, Monash University, Northways Road, Churchill, Victoria 3842, Australia.

Received: 17 June 2014 Accepted: 22 August 2014

Published: 4 September 2014

\section{References}

1. de Roodenbeke E, Lucas S, Rouzaut A, Bana F: Outreach Services as a Strategy to Increase Access to Health Workers in Remote and Rural areas: Technical Report No 2. Geneva: World Health Organization International Hospital Federation; 2011.

2. Department of Health and Ageing: Rural Health Outreach Fund-Service Delivery Standards: Rural and Regional Health Australia. Canberra: Australian Government; 2012 
3. O'Sullivan BG, Joyce CM, McGrail MR: Adoption, implementation and prioritization of specialist outreach policy in Australia: a national perspective. Bull World Health Organ 2014, 92:512-519.

4. Gruen RL, Bailie RS, Wang Z, Heard S, O'Rourke IC: Specialist outreach to isolated and disadvantaged communities: a population-based study. Lancet 2006, 368:130-138.

5. Australian Medical Workforce Advisory Committee: Sustainable Specialist Services: A Compendium of Requirements 2004 update AMWAC Report 2004.4 North Sydney: AMWAC; 2004

6. Australian Institute of Health and Welfare: Medical Workforce 2012. National Health Workforce Series no. 8. Cat. no. HWL 54. Canberra: AlHW; 2014.

7. 2006 Census of population and housing. http://www.abs.gov.au/census.

8. Hoy W, Kondalsamy-Chennakesavan S, Scheppingen J, Sharma S, Katz I: A chronic disease outreach program for Aboriginal communities. Kidney Int 2005, 68:S76-S82.

9. Turner AW, Mulholland W, Taylor HR: Funding models for outreach ophthalmology services. Clin Exp Ophthalmol 2011, 39:350-357.

10. eHealth Policy Analysis: Evaluation of the Medical Specialist Outreach Assistance Program and the Visiting Optometrists Scheme - Final report Volume 2 - Community Case Studies. Canberra: Department of Health and Ageing; 2011.

11. Cheng TC, Joyce CM, Scott A: An empirical analysis of public and private medical practice in Australia. Health Policy 2013, 111:43-51.

12. Gadiel D, Ridoutt L, Bune A, Cheang C, Cook K, Thiele D: Evaluation of outreach models of medical specialist service delivery. Human Capital Alliance International: Sydney; 2004

13. Health Policy Analysis: Evaluation of the Medical Specialist Outreach Assistance Program and the Visiting Optometrists Scheme - Final report Volume 1. Canberra: Department of Health and Ageing; 2011.

14. Health Workforce Australia: National Rural and Remote Workforce Innovation and Reform Strategy. Adelaide: Health Workforce Australia; 2013.

15. Health Workforce Australia: Health Workforce 2025 - Volume 3 - Medical Specialties. Adelaide: Health Workforce Australia; 2012.

16. Joyce C, Scott A, Jeon S-H, Humphreys J, Kalb G, Witt J, Leahy A: The "Medicine in Australia: Balancing Employment and Life (MABEL)" longitudinal survey - Protocol and baseline data for a prospective cohort study of Australian doctors' workforce participation. BMC Health Serv Res 2010, 10:50

17. Medicine in Australia: Balancing Employment and Life: Specialist. https:// mabel.org.au/mabelqw1.html.

18. The Australian Standard Geographical Classification (ASGC) Remoteness Structure. http://www.abs.gov.au/websitedbs/d3310114.nsf/home/ remoteness+structure.

19. Health Workforce Australia: Australia's Health Workforce Series - Doctors in Focus. Adelaide: Health Workforce Australia; 2012.

20. Chittleborough TJ, Lourensz K, Elliot M, Thomas P, Franzi S: Outreach surgical consulting services in North East Victoria. Aust J Rural Health 2013, 21:325-328.

21. Gruen $R$, Bailie R: Specialist clinics in remote Australian Aboriginal communities: where rock art meets rocket science. J Health Serv Res Policy 2004, 9:56-62

22. Cord-Udy N: The Medical Specialist Outreach Assistance Programme in South Australia. Australas Psychiatry 2003, 11:189-194.

23. McGrail M, Humphreys J, Joyce $C$ : Nature of association between rural background and practice location: A comparison of general practitioners and specialists. BMC Health Serv Res 2011, 11:63.

24. Cord-Udy N: Remote Area Indigenous Psychiatry: Not your usual day at the office. Australas Psychiatry 2006, 14:295-299.

25. Cheng TC, Scott A, Jeon S-H, Kalb G, Humphreys J, Joyce C: What factors influence the earnings of general practitioners and medical specialists? Evidence from the medicine in Australia: Balancing employment and life survey. Health Econ 2012, 21:1300-1317.

26. Gruen RL, Weeramanthri TS, Bailie RS: Outreach and improved access to specialist services for indigenous people in remote Australia: the requirements for sustainability. J Epidemiol Community Health 2002, 56:517-521.

doi:10.1186/1478-4491-12-50

Cite this article as: O'Sullivan et al:: Rural outreach by specialist doctors in Australia: a national cross-sectional study of supply and distribution. Human Resources for Health 2014 12:50.

\section{Submit your next manuscript to BioMed Central and take full advantage of:}

- Convenient online submission

- Thorough peer review

- No space constraints or color figure charges

- Immediate publication on acceptance

- Inclusion in PubMed, CAS, Scopus and Google Scholar

- Research which is freely available for redistribution
C Biomed Central 